
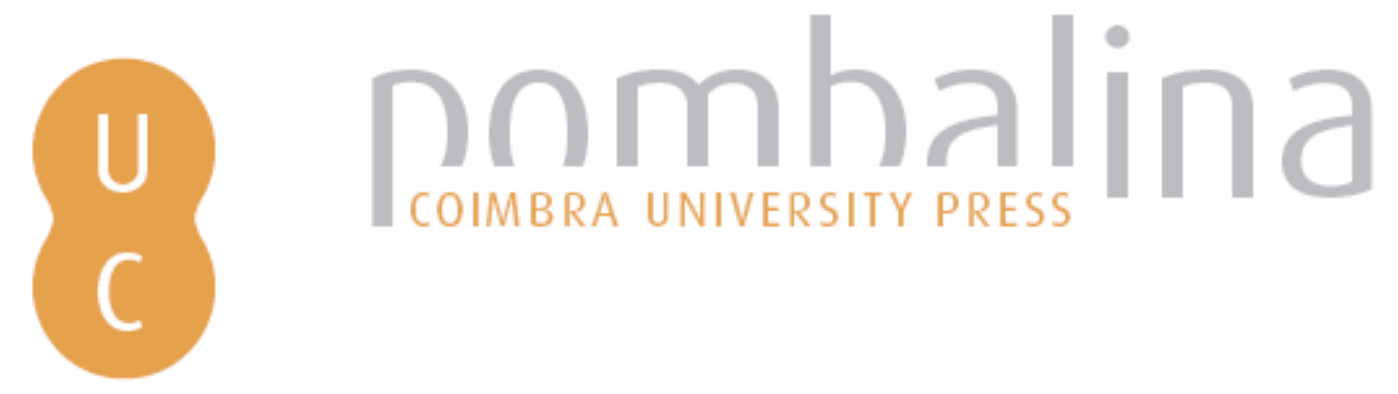

\title{
A aprendizagem pela conversa na formação de educadores: ecos de um caminho partilhado de aprendizagem, investigação e mudança
}

Autor(es): Lopes, Liliana

Publicado por: Imprensa da Universidade de Coimbra

URL

persistente: $\quad$ URI:http://hdl.handle.net/10316.2/41299

DOI: $\quad$ DOI:https://doi.org/10.14195/978 $\quad$ 289 26 1326-0_10

Accessed : $\quad$ 26-Apr-2023 11:12:27

A navegação consulta e descarregamento dos títulos inseridos nas Bibliotecas Digitais UC Digitalis, UC Pombalina e UC Impactum, pressupõem a aceitação plena e sem reservas dos Termos e Condições de Uso destas Bibliotecas Digitais, disponíveis em https://digitalis.uc.pt/pt-pt/termos.

Conforme exposto nos referidos Termos e Condições de Uso, o descarregamento de títulos de acesso restrito requer uma licença válida de autorização devendo o utilizador aceder ao(s) documento(s) a partir de um endereço de IP da instituição detentora da supramencionada licença.

Ao utilizador é apenas permitido o descarregamento para uso pessoal, pelo que o emprego do(s) título(s) descarregado(s) para outro fim, designadamente comercial, carece de autorização do respetivo autor ou editor da obra.

Na medida em que todas as obras da UC Digitalis se encontram protegidas pelo Código do Direito de Autor e Direitos Conexos e demais legislação aplicável, toda a cópia, parcial ou total, deste documento, nos casos em que é legalmente admitida, deverá conter ou fazer-se acompanhar por este aviso.

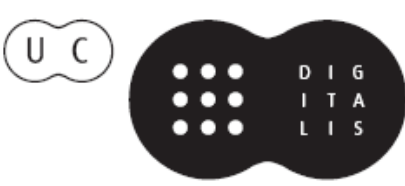




\title{
10.A APRENDIZAGEM PELA CONVERSA NA FORMAÇÃO DE EDUCADORES: ECOS DE UM CAMINHO PARTILHADO DE APRENDIZAGEM, I N V E S T I G A ÇÃ O E MUDANÇA
}

Liliana Lopes ${ }^{26}$

\begin{abstract}
Resumo
O texto dá a conhecer a trajetória de um grupo de formadores-investigadores criado no âmbito do Training of Trainers Course (ToT), um curso anual de formação avançada de educadores intervenientes em projetos sociais suportados pelo Programa Europeu Juventude em Ação. A demanda de se integrar uma vertente investigativa surgiu da necessidade de sistematizar dinâmicas de reflexão e (auto)avaliação preexistentes em torno do curso, no sentido de compreender o que suporta a aprendizagem não-formal dos seus participantes. Dessa forma, a aprendizagem pela conversa e a intervisão colocaram-se como ferramentas mediadoras do processo de integração intencional e explícita da investigação nas dinâmicas formativas dos educadores não-formais. Essas ferramentas inserem-se no contexto
\end{abstract}

${ }^{26}$ Associação Espaços - Projetos Alternativos de Mulheres e Homens Escola Superior de Educação do Instituto Politécnico do Porto http://associacaoespacos.blogspot.pt/ 
da investigação-ação participativa, uma vez que privilegiam princípios fundamentais de uma metodologia de conscientização: no potencial emancipatório dos processos de produção do conhecimento e no potencial transformativo da investigação pela construção de quadros interpretativos contextualizados e úteis para a resolução social de problemas comuns. Além disso, essa metodologia possibilita a todos os participantes autoria na produção de novas visões / novo conhecimento sobre o que suporta a aprendizagem no ToT. Nesse contexto, o registo dos conteúdos, processos e percursos das conversas ampliou as potencialidades formativas/investigativas do grupo, uma vez que os participantes puderam recorrer a esses registos para continuamente revisitar e reproblematizar as questões em jogo. Assim, as representações dos participantes foram sendo alicerçadas em produções grupais onde se articulam todos os discursos, produzidos por um coletivo de participantes-investigadores que foram tomando consciência do seu processo de aprendizagem - e de si, enquanto trabalhadores socioeducativos.

\footnotetext{
Abstract

This text presents the trajectory of a group of researching-trainers established under the Training of Trainers Course (ToT), an annual course for advanced training of educators involved in social projects supported by the Youth in Action European Programme. The need to systematize preexisting dynamics of reflection and (self) evaluation about the course lead to the integration of an investigative trend among the activities of the group. This investigative trend aimed to analyze what is in the basis of the participants' non-formal learning processes. Therefore, the conversational learning and the intervision were the intermediating tools of the explicit and intentional integration of the research
} 
in the training process of non-formal educators. These tools are embedded in the methodology of participatory action-research, since emphasize fundamental principles of awareness: in the emancipator potential of knowledge production processes and in the transformative potential of the research for the construction of contextualized and useful interpretative frameworks to collaboratively solve common problems. Besides, this methodology enables the authorship of participants in the production of new visions / new knowledge which supports learning in ToT. In this context, the registration of the conversations' content extended the training/investigative potentials of the group, since the participants were able to use these records to continuously revisit and discuss the issues at stake. Thus, the representations of the participants were being grounded in group productions which articulate all the speeches of a collective of participants-researchers that were becoming aware of their learning process - and themselves as socio-educational workers. 


\section{O ponto de encontro como ponto de partida}

O ponto de partida para o projeto de investigação/intervenção aqui descrito localiza-se nos processos de reflexão partilhada que os seus protagonistas iniciaram no âmbito do Seminário "Diálogo em Aprendizagem Não-formal: encontros entre a prática e a investigação", promovido em novembro de 2011 por uma rede europeia de educadores em educação não-formal - a Rede UNIQUE (United for Innovation and Quality in Education). Neste Seminário, pretendia-se refletir em torno da integração da investigação nos processos de educação não-formal promovidos pelos membros da Rede, consequência do reconhecimento de que a inovação e a melhoria da qualidade das suas práticas educativas assentam em processos de investigação capazes de produzir conhecimento relevante sobre as mesmas.

Para o efeito, a UNIQUE lançou uma chamada de peritos para a conceção e dinamização de workshops que fossem ao encontro das necessidades formativas manifestadas pelos participantes. A Associação Espaços propôs a realização do workshop "Quando Investigar é Aprendermos Juntos: Investigação Participativa pela Aprendizagem pela Conversa", com o qual se pretendia:

- proporcionar a aprendizagem experiencial da metodologia da aprendizagem pela conversa (Baker, Jensen, \& Kolb, 2002);

- evidenciar o carácter educativo e investigativo do processo vivenciado;

- perspetivar o seu potencial para a integração da investigação nas práticas educativas não-formais.

O trabalho desenvolvido com dois dos participantes no Seminário veio a ser o primeiro passo para o projeto "Training of Trainers integrated action-research", realizado no âmbito da edição 2012-2013 do Training of Trainers Course (ToT), um curso anual de 
formação avançada orientado para educadores intervenientes em projetos para a juventude no âmbito do Programa Juventude em Ação (PJA) da União Europeia (UE).

\section{O trabalho socioeducativo no âmbito do Programa Juventude em Ação}

Um dos desígnios principais do PJA é oferecer "[...] oportunidades para que os jovens adquiram competências [...]", pelo que se constitui como um "[...] instrumento essencial da aprendizagem não-formal $[\ldots]$ cuidadosamente planificada para fomentar o desenvolvimento pessoal, social e profissional [...]" dos jovens (Comissão Europeia, 2013, p. 7). Atendendo também às finalidades expressas do programa, depreende-se que as pessoas envolvidas na conceção e desenvolvimento de projetos ao abrigo do PJA, designadas por trabalhadores no setor da juventude, devem ter competências para conceber e desenvolver atividades de educação não-formal com jovens. Otten e Ohana (2009, p. 7) referem que os trabalhadores no setor da juventude devem ser capazes de trabalhar, de forma competente, no campo da educação intercultural, como uma forma específica de educação política, o que situa de forma clara os atores envolvidos no PJA num dos campos tradicionalmente associados à educação não-formal.

O conjunto de princípios que devem estar presentes na conceção e implementação de atividades de educação não-formal no âmbito do PJA, por forma a trabalhar no sentido da concretização das finalidades a que o programa se propõe, pode sistematizar-se do seguinte modo: abordagens participativas, centradas no aprendente e nas suas necessidades, aspirações e interesses; settings que promovem a aprendizagem no grupo de pares, em ambientes promotores de aprendizagem e diálogo interculturais; recurso 
a estratégias diversificadas e à complementaridade entre níveis de aprendizagem cognitiva, social e prática (Conselho Europeu \& Comissão Europeia, 2011, p. 5). Fennes e Otten acrescentam a este conjunto de princípios a promoção de "valores e práticas democráticos" (2008, p. 15).

\subsection{Competências para o trabalho no setor da juventude - competências para o trabalho socioeducativo}

Otten e Ohana (2009, pp. 5-7) salientam que o perfil de competências dos trabalhadores no setor da juventude deve suportar a missão global dos projetos desenvolvidos no âmbito do PJA, espelhada no conjunto de finalidades que atrás se sistematizaram. Propõem, então, que o desempenho das atividades destes atores no âmbito do programa implicará:

- o desenvolvimento de competências pessoais e profissionais que englobam saberes, atitudes e valores, e a capacidade para agir essas competências de forma autónoma - quando trabalham sozinhos com um grupo de jovens ou de outros educadores - e de forma colaborativa - quando integrados em equipas de formadores;

- um nível de maturidade pessoal e social que lhes permita desempenhar de forma bem sucedida tarefas complexas e gerir situações em contextos interculturais complexos, permeados de ambiguidade, contradições e ambivalências;

- o desenvolvimento de um pensamento reflexivo autónomo, crítico, analítico e não-dogmático, aliado à capacidade de autoperceção e autoanálise;

- a realização de uma ação reflexiva, que lhes permita a gestão das suas competências sem perder de vista os princípios e 
as abordagens metodológicas preconizados para os processos de educação não-formal que concebem e implementam;

- a capacidade para perceber os sujeitos, as situações comunicacionais, as interações que se desenrolam em contextos de educação não-formal, de modo a possibilitar processos sustentáveis de aprendizagem de acordo com as suas próprias necessidades, características e capacidades, em respeito pelos objetivos globais dos projetos que enquadram a sua ação socioeducativa.

A partir desta última competência, os mesmos autores salientam que pensar e agir reflexivamente exige, dos educadores não-formais no âmbito do PJA, mais do que capacidades pedagógicas, métodos de animação e técnicas de facilitação de aprendizagens (Otten \& Ohana, 2009, p. 6), remetendo para um quadro mais abrangente de competências sociais e relacionais destes profissionais. Neste sentido, apontam para a necessidade de proporcionar as condições necessárias para que os educadores não-formais possam, de forma autónoma e autodirigida, assumir a responsabilidade pelo seu desenvolvimento pessoal e profissional transversal e holístico, ou seja, pela sua formação contínua ao longo da sua vida e rentabilizando todos os seus contextos de vida e de trabalho.

\subsection{A formação de educadores no âmbito do Programa Juventude em Ação}

Atendendo ao perfil de competências preconizado para os educadores não-formais que trabalham no setor da juventude, e ao conjunto de princípios orientadores para as práticas educativas não-formais no seio do PJA, Fennes e Otten (2008) elaboraram uma sistematização das abordagens metodológicas consideradas adequadas ao desenvolvimento 
do que designam por "competências que combinam conhecimentos, atitudes e capacidades necessários ao trabalho no setor da juventude" (Fennes \& Otten, 2008, p. 16), de onde se destacam: abordagens orientadas para o processo e holísticas, dado o caráter multidimensional - cognitivo, social e prático - das competências a desenvolver; aprendizagem autodirigida, combinada com métodos focados na interação social entre pares, com recurso aos encontros interculturais como dispositivo de aprendizagem; aprendizagem experiencial, em que se reflete e analisa a partir da experiência, aprendendo fazendo (Fennes \& Otten, 2008, p. 17). Esta matriz orientadora das propostas formativas para estes trabalhadores-educadores não-formais é seguida no ToT, o curso de formação para formadores que operam no PJA em torno do qual se construiu o projeto de investigação e intervenção de que aqui se dá conta.

\subsection{Paradoxos e problemas emergentes da profissionalização do setor}

Ao nível das políticas europeias para a juventude, a formação destes educadores é considerada um eixo fundamental de atuação pelo seu impacto na qualidade da intervenção com a população jovem (Otten \& Ohana, 2009, p. 5). Analisando as recomendações e os quadros estratégicos para o setor, percebe-se que se configura como prioritário o desenvolvimento de um perfil qualificado, propondo-se mesmo a criação de um Quadro Europeu de Competências Genéricas para o trabalho no setor da juventude, que deverá orientar a organização de uma rede de ofertas formativas acreditadas (Comissão Europeia, 2010: 3), o que constitui um passo no sentido da consolidação de um movimento para a certificação e profissionalização do campo da educação não-formal no setor da juventude (Fennes \& Otten, 2008, p. 27; Otten \& Ohana, 2009, p. 7). 
Neste contexto, desenha-se uma tendência, paradoxal, de formalização dos processos de formação de educadores não-formais, mantendo-se, no campo discursivo, a crença de que a sua formação deve decorrer num sistema de princípios educativos coerentes com a sua prática educativa, em que as abordagens pedagógicas sejam consistentes com as competências a desenvolver, para que efetivamente sejam capazes de agir no quadro da educação não-formal. Esta ambiguidade gera tensões com consequências, já percetíveis, de erosão de alguns princípios da educação não-formal nos processos de formação destes educadores (Fennes \& Otten, 2008, p. 13).

As tensões resultantes para os processos de educação não-formal decorrem, genericamente, de duas dinâmicas paralelas: a criação de instrumentos de certificação e profissionalização, como quadros de competências para o trabalho no setor da juventude, ou mecanismos de acreditação de entidades e processos/percursos de formação - abrindo caminho a dinâmicas de subjugação dos processos de aprendizagem aos conteúdos e ao reconhecimento das aprendizagens, de hierarquização de saberes e papéis, de padronização de settings de formação e dispositivos de aferição; e a pressão para a massificação e contratualização da formação decorrente dos mecanismos europeus de financiamento - o que acarreta um potencial de institucionalização dos processos de aprendizagem, fragilizando o respeito pelo princípio básico da educação centrada no aprendente, assente em relações transparentes e securizantes capazes de promover a participação voluntária em processos democráticos, equitativos e cooperativos (Fennes \& Otten, 2008).

Os aspetos anteriormente referidos são uma evidência concreta daquilo que Lima e Afonso (2006, p. 222) designam como "dupla formalização - a formalização do não-formal em termos educacionais e a formalização do informal em termos organizacionais", destacando a dinâmica de reciprocidade entre a formalização de iniciativas originalmente situadas na educação não-formal e a 
crescente estruturação, hierarquização e regulação dos processos no seio de entidades originalmente mais tendentes à flexibilidade, à improvisação e mesmo à ambiguidade.

Reconhece-se que a qualidade dos processos educativos não-formais, em contexto europeu, deve ser equacionada em três níveis (Fennes \& Otten, 2008, p. 21):

- o nível macro, dos sistemas e das políticas educativas de âmbito regional, nacional e europeu:

- o nível meso, das instituições e organizações que promovem as ações socioeducativas;

- o nível micro, dos processos de ensino-aprendizagem.

No que respeita ao nível micro, Gruber e Schlögl (2007, cit. em Fennes \& Otten, 2008, p. 20) ressalvam que o sucesso educativo não se relaciona linearmente com a qualidade do processo educativo, daqui resultando que se este se pode assegurar e aferir, isso não significa que está concomitantemente assegurada a aprendizagem, ou que esta se pode prever. Não obstante, também não será legítimo esperar que os processos de aprendizagem sejam bem-sucedidos do ponto de vista da aquisição e desenvolvimento de competências, sem que se cuide a organização dos contextos e interações educativos de modo a que sejam favorecedores das aprendizagens (Fennes \& Otten, 2008, p. 21). Emerge então um outro paradoxo no coração da tendência de profissionalização do setor do trabalho socioeducativo neste setor: a qualificação dos trabalhadores reside no sucesso de processos de aprendizagem com vista ao desenvolvimento de competências-chave reconhecíveis e certificáveis, mas essas aprendizagens são, em larga medida, não inteiramente planificáveis nem controláveis, porque assentam em dimensões relacionais e psicossociais da pessoa. Os processos formativos podem ser continuamente desenhados, avaliados e reconfigurados 
para que sejam congruentes com critérios de qualidade definidos para a educação não-formal, mas nem por isso será garantido o sucesso aferido em termos de aprendizagens e qualificação dos educadores em formação.

\section{O Training of Trainers Course: proposta formativa e espaço de aprendizagens}

É neste contexto que a equipa responsável pela conceção e dinamização do ToT pretende compreender melhor em que medida o curso é, e poderá continuar a ser, uma "oferta [formativa] de elevada qualidade para formadores, educadores e facilitadores em busca de mais competência, de mais segurança, de mais confiança, de mais contactos, de mais profissionalismo ou de mais clareza para as próximas etapas das suas carreiras profissionais" (Hofmann, 2010, p. 3). Para a equipa, aferir e melhorar a sua eficácia, coerência e qualidade requeria levar a cabo um processo de investigação que permitisse compreender o que suporta a aprendizagem não-formal dos participantes no ToT, já que o suporte à aprendizagem autodirigida dos participantes constitui o cerne desta proposta formativa.

O ToT realiza-se anualmente desde 1999/2000 com a finalidade de contribuir para melhorar a qualidade dos processos de formação integrados nos programas da UE no setor da juventude ${ }^{27}$ (Hofmann, 2010 , p. 3), na medida em que se orienta para a formação avançada de trabalhadores socioeducativos que implementam atividades de educação não-formal no âmbito do próprio PJA.

27 O ToT iniciou-se ainda sob alçada do Programa "Juventude", implementado entre 2000 e 2006, que antecedeu o Programa Juventude em Ação (cf. http:// ec.europa.eu/youth/index en.htm). 
Da análise dos documentos de referência do curso $^{28}$ - nomeadamente os Princípios Orientadores da Equipa de Formadores e os Princípios do Processo de Mentoria - podemos perceber que as três componentes do ToT assentam na aprendizagem pela experiência - com fortes marcas do contributo de Kolb (1984) para a conceptualização e práticas da aprendizagem experiencial - e no potencial de aprendizagem que reside no encontro e na interação socialmente contextualizados com o outro - integrando elementos do autodesenvolvimento da identidade que, como propõe Jarvis (1987), está no centro da aprendizagem dos adultos. A dimensão individual da aprendizagem - encarada como processo pessoal e interno experienciado por cada indivíduo, na linha da tradição humanista da abordagem não-diretiva à facilitação do desenvolvimento pessoal de Carl Rogers (1969) - é igualmente reconhecida e apoiada pela introdução no curso de um processo de mentoria individual, sendo para o efeito atribuído um mentor (de entre a equipa de formadores) a cada participante.

De forma transversal, a abordagem metodológica privilegia princípios da aprendizagem autodirigida (Knowles et al., 1984), articulada com o consequente processo de autoaferição das aprendizagens, donde decorre que os formadores e o grupo de pares assumem o papel de facilitadores dos processos de aprendizagem de cada participante. O curso, como um todo - metodologias, estratégias, propostas de trabalho - está organizado para assumir a função de suporte às trajetórias autodirigidas de aprendizagem e formação dos participantes, em linha com o princípio geral de centramento no aprendente que as perspetivas para a educação não-formal no seio do PJA advogam, e articula-se com a assunção de que cada pessoa tem formas preferenciais de aprendizagem, pelo que ao longo do

${ }^{28}$ Disponíveis em http://www.salto-youth.net/rc/training-and-cooperation/tc-rc-nanetworktcs/tot/tot-backgound-docs/ 
ToT se propõem diferentes abordagens e estratégias para melhor responder às necessidades e interesses de cada participante.

Consultando a "carta de compromissos" 2 que a equipa do ToT elaborou como matriz de orientação para a conceção e dinamização do curso, podemos aceder à apropriação concreta que a equipa responsável pelo ToT fez, ao longo dos seus 14 anos de trabalho em conjunto, dos princípios e abordagens metodológicas para a educação não-formal que têm vindo a ser preconizadas ao nível das políticas europeias para a o trabalho no setor da juventude e para a educação não-formal. A perspetiva educativa partilhada que foi sendo construída corporiza-se na sistematização de um núcleo duro de objetivos operatórios que a equipa definiu como centrais para o desenvolvimento do ToT:

- desenhar um curso que tem em conta o facto de que diferentes pessoas têm diferentes formas preferenciais de aprendizagem;

- apoiar os participantes a conectar com as suas necessidades pessoais de aprendizagem, com as formas como aprendem melhor e a assumir a responsabilidade por atingir os seus objetivos de aprendizagem;

- favorecer o desenvolvimento de um ambiente de aprendizagem em parceria com os participantes;

- promover ocasiões para observar e refletir em torno dos processos e acontecimentos em contexto de equipa de trabalho e em contexto de grande grupo;

- promover oportunidades de prática recorrentes;

- promover uma cultura grupal baseada em valores como a participação, a reflexão crítica, a diversidade, a expressão humana multidimensional, a inclusão, a solidariedade e a cooperação.

A análise destes compromissos reforça a perceção da centralidade da função de suporte à aprendizagem autodirigida dos participantes, mas 
aponta ainda para um aspeto que lhe é inerente: a responsabilização do aprendente pela sua aprendizagem, colocada pelos autores Fennes e Otten em termos de "propriedade do processo e dos resultados da aprendizagem por parte dos aprendentes" (2008, p. 15). Neste sentido, para a operacionalização da função de suporte à aprendizagem autodirigida, o ToT privilegia um eixo de trabalho especificamente orientado para "apoiar os participantes a tornarem-se aprendentes autónomos competentes" (Hofmann, 2010, p. 30), e portanto capazes de dirigir os seus próprios processos de aprendizagem. O suporte ao desenvolvimento da competência para aprender autonomamente serve, por sua vez, o propósito maior de apoiar os participantes no desenvolvimento de competências para a facilitação da aprendizagem de outras pessoas com quem trabalharão em projetos no âmbito do PJA.

O ToT prevê também uma componente de conceção e implementação de um projeto prático de formação pelos participantes que, suportada pelas demais componentes, serve de uma forma mais específica os interesses organizacionais do PJA - não só porque proporciona a multiplicação das ações implementadas no âmbito do programa, mas também, e principalmente, porque permite um retorno direto dos processos de aprendizagem e reflexão sobre a conceção e a implementação de atividades no âmbito do próprio programa, contribuindo assim para a evolução contínua do PJA. Este aspeto aproxima a abordagem educativa do ToT da metodologia de investigação-ação-participativa (Reason \& Bradbury, 2001): pela participação no ToT, formadores no âmbito do PJA foram evoluindo - aprendendo - e (re)construindo o conhecimento - de si, dos processos de educação e de aprendizagem, do próprio PJA - a partir do qual contribuem para a transformação do PJA através da transformação das suas conceções e práticas. Por via desta dinâmica, o PJA prefigura-se como uma organização aprendente (Watkins \& Marsick, 1993), tanto quanto, e na medida em que, as pessoas que trabalham nos projetos do programa são sujeitos em aprendizagem na ação. 


\subsection{A emergência da necessidade de investigar}

Ao longo dos anos, o ToT manteve os seus contornos fundamentais no que respeita à sua estrutura e às metodologias de trabalho. A equipa responsável pela conceção e implementação do curso trabalha junta há vários anos, e esta estabilidade tem-lhes permitido o desenvolvimento e consolidação de uma perspetiva educativa partilhada. No entanto, esta mesma estabilidade pode ser vista também como um fator que acarreta riscos acrescidos de cristalização ou dogmatização dos princípios e práticas estruturantes do ToT, e a equipa tem consciência desse risco.

Analisando os conteúdos da publicação que faz o balanço retrospetivo dos 10 anos do ToT (cf. Hofmann, 2010), encontramos evidência de que a equipa procura ativamente manter uma trajetória sistemática de reflexão e (auto)avaliação, pese embora sustentada em processos de caráter mais intuitivo do que sistemático, que por um lado assentam na informação recolhida por meio dos procedimentos formais de avaliação do curso - que consistem em inquéritos por questionário administrados aos participantes, centrados na recolha da sua perceção acerca do impacto do curso nas suas competências e trajetórias $^{29}$ - e que por outro lado se baseiam na discussão de perceções e representações construídas pelos membros da equipa, sem recurso a procedimentos sistemáticos de recolha e análise de informação sobre a qual sustentar mais solidamente as conclusões elaboradas. A cada edição do curso, e à medida que se ia estabelecendo um consenso em torno da necessidade de desenvolver e implementar processos de formação de elevada qualidade certificada, devidamente orientados para públicos específicos envolvidos

29 Dados da avaliação da edição 2010/2011 do ToT e dados do impacto da participação na trajetória dos participantes disponíveis para consulta e transferência em http://www.salto-youth.net/rc/training-and-cooperation/tc-rc-nanetworktcs/tot/. 
no trabalho no setor da juventude na Europa (García López, 2007), a mesma questão permanecia latente, e a resposta por desocultar: o que suporta a aprendizagem dos participantes no ToT?

A integração da investigação no perfil da equipa e no seu trabalho educativo no ToT foi encarada como uma necessidade, mas acima de tudo como um desafio de aprendizagem, pois era claro para a equipa que isso exigia ampliar e aprofundar competências para a investigação. Não havendo oferta formativa capaz de responder às especificidades das suas necessidades de aprendizagem, a procura conduziu à presença de dois dos seus membros no Seminário "Diálogo em Aprendizagem Não-formal: encontros entre a prática e a investigação", e ao seu posterior interesse em perspetivar a integração da aprendizagem pela conversa e da intervisão como modos de formação contínua autodirigida, e como modo de investigação integrada no ToT de forma transversal a todos os processos de conceção, implementação e avaliação do curso.

\section{A investigação/intervenção no ToT: caminhos de um colectivo aprendente}

\subsection{A aprendizagem pela conversa como dispositivo de formação e investigação em educação não-formal}

A metodologia de aprendizagem pela conversa (Baker, Jensen, \& Kolb, 2002) baseia-se no modelo de aprendizagem a partir da experiência desenvolvido por Kolb (1984), que concebe a aprendizagem como um processo pelo qual é criado conhecimento através da transformação da experiência. O modelo contempla quatro fases: 
1. Experiência concreta;

2. Observação e reflexão;

3. Conceptualização abstrata;

4. Experimentação em novas situações.

A conceção da aprendizagem pela experiência segundo este modelo prevê que o processo de aprendizagem possa começar em qualquer uma das fases, com a ressalva de que o movimento cíclico desse processo é unidirecional (de 1 para 4). Kolb identifica quatro estilos de aprendizagem, correspondentes às quatro fases deste modelo, propondo que cada pessoa aprende "melhor" através da combinação de dois destes quatro estilos:

1. Divergência (aprender observando a experiência vivida);

2. Assimilação (aprender através da reflexão, conceptualização e teorização);

3. Convergência (aprender através da ação, aplicando conceitos e teorias);

4. Acomodação (aprender através da experiência vivida na ação).

A metodologia de aprendizagem pela conversa acentua a dimensão coletiva do processo cíclico da aprendizagem experiencial. Em contexto de grupo, a aprendizagem torna-se mais completa e complexa, não só devido às diferenças de pontos de vista e saberes, mas também devido à diversidade nos estilos de aprender em presença, e à pluralidade dos recursos mobilizáveis pelo e para o grupo: experiências vividas, observações e reflexões, teorizações e ações.

De modo abreviado, nesta metodologia pretende-se a produção participada e democrática de conbecimento ligado ${ }^{30}$, pelo que se desenvolve conectando as pessoas e os seus processos de aprendizagem

30 No original: connected knowledge (Baker, Jensen \& Kolb, 2002). 
no espaço da conversa. Cada participante experiencia internamente um processo de aprendizagem social quando envolvido numa conversa: as suas posições cognitivas e emocionais serão inicialmente explícitas para si, para então serem transformadas pela conexão com as posições dos outros, num processo contínuo de atribuição de um significado socialmente aceite no contexto grupal de produção de conhecimento, e de integração deste conhecimento produzido pelo grupo nos seus próprios pensamento e discurso (Baker, Jensen \& Kolb, 2002). Este potencial para a autoconsciencialização, e para a reconstrução de conceitos e entendimentos é um potencial para a aprendizagem (Koning, Múrias, Ribeiro, Carvalho \& Lopes, 2012, p. 19).

O processo de aprendizagem pela conversa proporciona um espaço fluido adequado para aprofundar a consciência, desfazer ideias feitas e fazer circular novas ideias (Koning et al., 2012, pp. 17-20). Um espaço onde as pessoas encontrem a possibilidade de discutir e refletir sobre as suas experiências: conversar com o objetivo de encontrar novos sentidos e deixar emergir novos conhecimentos.

Apesar de se pretender fluido, o espaço da conversa deve ser estruturado, de modo a manter-se um espaço seguro para a partilha, e a permitir os aspetos inerentes à aprendizagem narrativa: hermenêutico - contar, formular e reconhecer intenções, objetivos e resultados; crítico-analítico - problematizar as narrativas contadas para analisar o seu contexto político-cultural regulador-dominante ou emancipador-crítico; e pragmático - que consiste na formulação de alternativas para perspetivar a ação (Nijk, cit. em Koning, 2009, p. 89). Baker, Jensen e Kolb (2002) distinguem cinco dimensões que o estruturam. Cada dimensão constitui uma tensão dialética apresentada num continuum, cujos polos são valorizados de forma não hierarquizada:

1. Apreensão (experiência) e compreensão (saberes);

2. Reflexão (intenção) e ação (extensão); 
3. Discurso epistemológico (saberes cognitivos) e recurso ontológico (saberes tácitos);

4. Individual e relacional;

5. Necessidade de ter estatuto (ranking) e solidariedade (conexão).

Quanto mais diversas forem as perspetivas expressas durante a conversa, mais atenção deve ser dada a este espaço, para que seja um espaço recetivo que permita criar uma base comum no meio da tensão dialética. Os polos devem ser mantidos em equilíbrio, de modo a que se possa dar valor aos contributos diversos - e eventualmente conflituais - das pessoas que participam na conversa (Koning, 2012, p. 38). Exige-se uma abordagem integradora das tensões, o que implica vivenciá-las ao longo do continuum dialético, e aprender com o que surge no espaço entre os extremos. A procura dos balanços adequados pode passar pela organização de ciclos de conversas com diferentes grupos, nos quais os participantes possam explorar e reconhecer as suas zonas de conforto no espaço de conversação, os seus processos de tomada de voz e de escuta, os seus processos de aprendizagem na interação com o outro. O objetivo é que todos possam formular novas narrativas recorrendo ao potencial de aprendizagem que reside no discurso/ação, na escuta/reflexão, bem como em cada uma das restantes tensões que atravessam as conversas.

A partir destas considerações, é clara a forte congruência entre a aprendizagem pela conversa e as práticas e princípios educativos que estruturam o ToT.

\subsection{Intervisão e supervisão: espaços de aprendizagens e de investigação}

Como se referiu, o trabalho socioeducativo não pode ser perspetivado apenas como uma função, mas também como um papel pessoal, 
um papel que está muito ligado às características particulares de cada pessoa. Com base neste desenvolvimento, Furrusten (2003, cit. em Emmerick, 2012, p. 92) introduziu o conceito de profissão frágil. Um profissional frágil tem de encontrar o seu caminho no meio da tensão que ocorre entre dois polos: ele é cada vez mais forçado a encontrar o seu próprio caminho entre a pressão de sistemas de controlo cada vez mais restritivos. Estes sistemas baseiam-se em conhecimento académico e técnico-profissional - modus I e modus II - e deixam muito pouco espaço para o aspeto vulnerável da condição humana, na qual o conhecimento existencial e moral - modus III - é importante (cf. Kunneman, 2005, cit. em Koning, 2009, p. 96).

Há uma tendência crescente na sociedade para procurar o controlo no conhecimento técnico-científico, sem conexão ao conhecimento existencial e moral que tem que ser parte integrante do desenvolvimento pessoal e profissional. As descrições de práticas profissionais evidenciam que este movimento ético é um processo de aprendizagem de compreensão não-linear (Marks-Tarlow, 2008; Sachs, 2009; Witteman, 2010, cit. em Emmerick, 2012, p. 93). Esta aprendizagem conecta-se com a pluralidade da vida humana, na qual o conhecimento é procurado em função do aqui e agora de uma dada situação, de um dado desafio profissional, de uma necessidade que o torna relevante e útil, reportando-se também aos pressupostos da construção de conhecimento dentro dos princípios da investigação-ação participativa (Reason \& Bradbury, 2001). Diz também respeito a práticas de aprendizagem nas quais há espaço para o desenvolvimento de uma profissionalidade frágil, para uma literacia profissional que não se relaciona apenas com aprendizagens, mas também com a capacidade de aprender a aprender ao longo da vida e através da vida profissional.

Abordar verdadeiramente a questão básica que Hannah Arendt levanta na introdução de $A$ Condição Humana (2001), "O que estamos a fazer?", e assim encarar a complexidade, é um movimento 
ético que apenas se faz de forma lenta e com grande esforço. O espaço em branco (Emmerick, 2012, p. 93), espaço para deixar as coisas indefinidas por algum tempo, criando espaço para aquilo que emerge, é algo que está a desaparecer cada vez mais das organizações, tal como da sociedade em geral. No trabalho, as pessoas que têm de gerir situações complexas como são os processos de educação e aprendizagem, têm cada vez menos oportunidades para abrandar o ritmo, discutir e refletir sobre a melhor forma de lidar com as questões complexas. Há uma forte tendência para lidar com a complexidade através do controlo e de sistemas de coordenação, desvalorizando o espaço em branco que, ao contrário do que se assume no seio das organizações, não é inatividade e não é um luxo. É essencial para lidar com questões complexas, e é essencial para que se tenha em conta que educar e aprender são atividades humanas, nas quais as pessoas não são uma categoria, mas uma pluralidade.

Criar espaço para o espaço em branco é uma forma de assegurar que aquilo que há de único em cada um de nós terá o espaço de que necessita. Onde não há espaço para falar e para investigar a complexidade das questões, espaço para criar novos significados nas palavras e entre elas, espaço para a emergência de novo conhecimento, o jogo da linguagem dominante - e, neste caso, dos modelos de modernização e de gestão dos recursos humanos na educação - funciona como uma prisão. Segundo Emmerick (2012, p. 94) isto significa que o espaço em branco também tem uma dimensão ética e política, funcionando como um espaço performativo para os processos de aprendizagem existencial e moral, em relação direta com as questões técnicas e organizacionais associadas aos processos educativos e de aprendizagem que os trabalhadores socioeducativos despoletam e promovem.

Parece, então, importante sublinhar a importância dos trabalhadores socioeducativos disporem de lugares de reflexão sobre as suas práticas como forma de desenvolvimento pessoal e profissional e, consequentemente, de qualificação da sua ação de forma coerente 
com um paradigma de transformação social. A supervisão, enquanto possibilidade de formação de profissionais reflexivos, quer se desenvolva individualmente ou em grupo, pode desempenhar este papel. Face à existência de vários modelos de formação, a conceção de Lemay, para quem o objetivo da supervisão é "ajudar o educador a obter uma melhor compreensão de si próprio na relação com o trabalho que se efectua" (Capul \& Lemay, 2003a, p. 97), afigura-se como particularmente coerente com um processo formativo afim dos processos que os trabalhadores socioeducativos deverão despoletar na sua prática profissional. A supervisão, não no sentido de um controlo, mas no sentido de um "olhar sobre as suas próprias acções" (Capul \& Lemay, 2003a, p. 97), pode, deste modo, apoiar o educador nesta tomada de consciência, no (re)conhecimento das suas ressonâncias afetivas, na avaliação das suas atitudes e na melhor utilização dos seus próprios recursos, adquirindo aos poucos o rosto de uma autossupervisão regularmente alimentada pelo encontro com o supervisor.

Por outro lado, e nesta mesma linha da promoção de processos autogestionados de auto e heteroformação entre pares, Emmerick propõe a intervisão como um "espaço em branco na medida em que cria espaço, no tempo e no espaço, para explorar o branco que há entre as linhas da narrativa de vida dos profissionais" (2012, p. 94). Segundo a autora, intervisão pode definir-se correntemente como procedimentos entre pares através dos quais se fornecem feedbacks críticos e apoiantes, numa base mútua, para a melhoria das competências profissionais, em que todos assumem responsabilidade pelo desenvolvimento do(s) outro(s), desenvolvendo-se assim a sua capacidade de autorregulação como profissionais. Estas competências podem ser melhoradas de várias formas, mas um aspeto importante é o desenvolvimento da profissionalidade frágil, em que os participantes são convidados e apoiados na procura do conhecimento existencial que conseguem ler nas entrelinhas da sua própria biografia. 
Para o facilitador, o foco principal está na manutenção do equilíbrio certo entre estrutura e "o nada", entre palavras e silêncio. É preciso haver fronteiras, e é preciso haver espaço livre. É tal como um espaço em branco físico: o branco não significa nada sem o texto que o rodeia, o texto adquire significado (subtexto) pelo branco. Há uma dinâmica contínua, uma transição contante entre ordem e surpresa. As cinco dimensões respeitantes à aprendizagem pela conversa (Baker, Jensen \& Kolb, 2002) assumem aqui uma importância essencial, pelo facto de sustentarem um conjunto de questões que devem ir pautando os sentidos de desenvolvimento dos grupos em intervisão:

- há um equilíbrio saudável entre a experiência do aqui e agora e o conhecimento conceptual que se refere ao exterior, ao passado?

- na reflexão sobre as experiências práticas dos participantes, há um equilíbrio entre ação e reflexão?

- a conversa foca-se no que se está a fazer e também em como se está a ser?

- há espaço para as necessidades do indivíduo e para a relação entre todos os participantes na conversa?

- há espaço tanto para o estatuto (respeito pela integridade de cada pessoa presente) como para a solidariedade?

A intervisão pode, então, decorrer no interior de processos de aprendizagem pela conversa, desde que haja uma intencionalidade de centrar o espaço conversacional nas questões definidas pelo grupo para o seu desenvolvimento profissional, podendo esta metodologia de aprendizagem experiencial e narrativa constituir-se como uma abordagem não-formal para a autoformação contínua dos trabalhadores socioeducativos. A opção pelos processos de supervisão pode também ser incorporada por via da participação do supervisor externo nos processos conversacionais, podendo 
inclusivamente conceber-se um esquema de complementaridade entre ambos os processos - intervisão e supervisão - aliando o intuito de construir um caminho de autonomização dos educadores na sua formação a partir da prática, à mais-valia de aportar uma visão externa para enriquecer e complexificar o discurso e os entendimentos acerca da prática socioeducativa.

\subsection{A trajetória do grupo de educadores-investigadores}

A trajetória deste projeto iniciou-se com a intencionalidade de dotar a equipa do ToT de competências para encetarem processos de investigação em torno do (e integrados coerentemente no) curso que concebem e que implementam anualmente. A aprendizagem pela conversa e a intervisão foram as ferramentas que mediaram uma trajetória que culminou com a transformação do ToT num processo ele mesmo de integração intencional e explícita da investigação nas dinâmicas formativas dos educadores não-formais. Formulou-se uma proposta concreta para integrar a investigação nos processos estruturantes do curso, sem que isso alterasse a identidade do ToT enquanto oferta formativa para educadores não-formais no setor da juventude, adotando-se a aprendizagem pela conversa como modo de investigação e aprendizagem integradas no curso.

As conversas decorreram entre maio de 2012 e setembro de 2013. Ao longo do tempo, os objetivos específicos para cada conversa foram sendo definidos pela própria equipa de formadores do ToT, privilegiando:

- a problematização do lugar da investigação nos processos educativos e de aprendizagem, a partir da exploração das experiências de formação e aprendizagem em que os formadores participaram no passado; 
- a identificação de abordagens e metodologias de investigação congruentes com processos de construção de conhecimento por parte de sujeitos envolvidos em atividades de formação e aprendizagem;

- a definição de prioridades e objetivos para a investigação em torno do que suporta a aprendizagem no ToT;

- a definição de opções metodológicas, de calendário e das tarefas associadas à operacionalização do plano traçado para a investigação;

- a identificação das competências necessárias à realização das tarefas de investigação, e atribuição de tarefas aos membros da equipa consoante o seu perfil de competências.

Em agosto de 2012, a equipa chegou a entendimentos partilhados capazes de sustentar a transformação da sua ação, e consequentemente do ToT enquanto proposta formativa que haveria de consubstanciar a sua vocação investigativa:

- conhecer os processos de aprendizagem no ToT exige aceder às representações de quem aprende no ToT, não basta partir das perceções de quem o desenha porque se corre o risco de perpetuar crenças e entendimentos não sustentados pela experiência de aprendizagem no curso, e porque há uma crença de base na epistemologia construtivista;

- a avaliação sistematizada do ToT, através de inquérito por questionário aos participantes, não permite à equipa conhecer o processo de aprendizagem no curso a partir de quem o protagoniza, porque não se recolhe a informação adequada à compreensão de processos, à sua descrição e à posterior interpretação, mas apenas à valoração que cada participante faz da sua experiência pessoal; 
- os princípios e metodologias de trabalho no ToT permitem aos participantes refletir, analisar e produzir conhecimento - individualmente e em grupo - acerca das formas como aprendem, das suas necessidades para o processo de aprendizagem, das formas como reconhecem as aprendizagens, mas os registos elaborados são individuais e para utilização individual, não se chegando a formular entendimentos partilhados e tendentes a uma conceptualização interpretativa e significada pelo e para o grupo;

- procedendo ao registo e análise do conhecimento produzido pelos participantes, sem comprometer a confidencialidade das partilhas, é possível começar a responder à questão de partida - o que suporta a aprendizagem no ToT? - a partir do conhecimento produzido pelos participantes em relação ao que vivenciam enquanto aprendentes no ToT;

- a experiência da equipa com a metodologia de aprendizagem pela conversa permitiu percebê-la como profundamente coerente com a abordagem educativa na base do ToT, e reconhecer o seu potencial para simultaneamente organizar a investigação que se pretende incorporar no desenho do curso, já que permite a produção e registo de informação útil e relevante.

O desafio para a equipa foi, então, encontrar e rentabilizar os pontos de convergência entre os objetivos da investigação, as abordagens metodológicas no ToT e a aprendizagem pela conversa enquanto modo de investigação e formação. Foi facilmente percebida a possibilidade de conversão de momentos do ToT em momentos de aprendizagem pela conversa, quer aqueles que se desenvolvem em contexto grupal, quer aqueles que se desenvolvem a pares - sejam pares de participantes, sejam os momentos de mentoria. 


\subsection{A investigação-ação participativa como horizonte de integração metodológica}

As voltas em espiral sobre o ciclo de aprendizagem experiencial, e a intencionalidade explícita de produção partilhada de novo conhecimento sobre questões concretas, de modo a redefinir conceitos e transformar práticas e contextos, permitem enquadrar a aprendizagem pela conversa no campo da investigação-ação participativa (IAP), já que se privilegiam os seus princípios fundamentais: o potencial emancipatório dos processos de produção de conhecimento pelo e para o grupo, que permitem "tornar-se sujeito através do exercício da palavra" (Koning et al., 2012, p. 21); e o potencial transformativo da investigação pela construção de quadros interpretativos altamente contextualizados, úteis para a resolução social de problemas comuns.

$\mathrm{Na}$ tradição da IAP, as abordagens conversacionais privilegiam uma das suas pedras de toque: possibilitar a todos os participantes autoria na produção de novas visões/conhecimento (Bogdan \& Biklen, 1994), neste caso em torno do que suporta a aprendizagem no ToT. Este é um argumento central na proposta de recurso à aprendizagem pela conversa como modo de investigação neste curso: cada participante vivencia processos de aprendizagem social nos ciclos de conversas, e ao mesmo tempo está envolvido na produção do conhecimento que se promove nas conversas.

O registo dos conteúdos, processos e percursos das conversas ampliou as possibilidades de recurso à aprendizagem pela conversa como modo de investigação e de aprendizagem integrado nos processos de intervisão, já que os participantes puderam recorrer ao material recolhido para continuamente revisitar e reproblematizar as questões em jogo, usando a sua palavra como interlocutor, na linha do sujeito nómada de Braidotti (2004, cit. em Koning, 2006, p. 238), gerando-se novos ciclos de investigação e aprendizagem 
em IAP. À medida que foram decorrendo as conversas no seio de grupos de composição variável, novas construções se foram produzindo a partir de uma multiplicidade de contributos, e das próprias produções coletivas anteriores. As representações dos participantes foram sendo alicerçadas em construções grupais onde se articulavam todos os discursos, produzidos por um coletivo de participantes-investigadores que foram tomando consciência do seu processo de aprendizagem e de si, enquanto trabalhadores socioeducativos.

\section{Um caminho na senda da conscientização}

Apesar da aprendizagem pela conversa privilegiar a "formulação narrativa na primeira pessoa" e não imediatamente "a conscientização unívoca de um grupo oprimido, que conjuntamente assumiria a ação para a transformação social" (Macedo \& Macedo, 2012: 234), é possível reforçar a possibilidade de conscientização implícita ao processo (Koning et al., 2012, p. 27). Tal como a metodologia de conscientização (Freire, 1979), a aprendizagem pela conversa exige e constrói uma base democrática e equitativa de acesso à palavra e construção de sentidos, sendo ambas conceptualizadas como movimentos cíclicos que se podem sobrepor quando se assume a intencionalidade de "desenvolver um olhar crítico em cada participante" (Koning, 2009, p. 89), promotor da construção de práticas inovadoras. Nesse sentido, em complementaridade com ciclos de conversação, pode introduzir-se a possibilidade de problematização a partir de textos-desafio, e a perspetivação da ação transformadora num grupo que partilha um mesmo universo temático e se confronta com problemas comuns. No sentido de substanciar uma militância pela emergência de um trabalho socioeducativo transformativo, emancipatório e efetivamente promotor de uma melhor qualidade de vida para todos, a alavancagem do potencial de conscientização 
da aprendizagem pela conversa é um imperativo ético e um compromisso com um paradigma de intervenção por um mundo mais igualitário, justo e democrático. Nesse sentido, a aprendizagem pela conversa poderá desenhar-se com processo educativo, ele mesmo transformativo dos grupos em formação, despertando um pensamento crítico e pragmático partilhado por coletivos de trabalhadores socioeducativos, que nela encontrem as dinâmicas geradoras de energia para a transformação das suas práticas no sentido de um compromisso com a transformação social, no quadro de um trabalho socioeducativo filiado no paradigma socialista-coletivista (Payne, 2002).

Não se pretendendo aqui imputar exclusivamente aos trabalhadores socioeducativos a responsabilidade da transformação do campo por via da transformação das suas conceptualizações em torno do seu trabalho, dos processos de educação e aprendizagem, e do sentido do desenvolvimento humano e social, a verdade é que este outro patamar de objetivos esteve sempre presente como finalidade(s) ulterior(es). Em momentos de profunda crise do modelo social dominante, e de descrédito em relação às possibilidades de mudança, importa recuperar, trazer à luz, a responsabilidade que reside em cada pessoa e em cada lugar de ação socioeducativa para despoletar dinâmicas de transformação social, pelo facto de haver sempre margens de autonomia no exercício profissional das quais não se pode abdicar.

A assunção da responsabilidade, e dir-se-á mesmo do potencial de liderança ou agência partilhada, exige dos trabalhadores socioeducativos disponibilidade para se trabalharem a si mesmos para além daquilo que lhes é proposto no período da sua formação académica inicial, num esforço contínuo de tomada de consciência dos conceitos, representações, posicionamentos ideológicos e éticos a partir dos quais se consubstanciam as suas práticas e os seus discursos. A intervisão e a aprendizagem pela conversa permitem 
integrar no processo formativo a desocultação das aprendizagens realizadas a partir e na prática, dos processos pelos quais estas acontecem, e dos sentidos e princípios que presidem ao desenvolvimento pessoal, profissional e social em curso. Este é o primeiro passo para a tomada de consciência da dimensão política da ação socioeducativa, e para a definição autónoma e consciente dos sentidos das transformações pessoais, profissionais e sociais com as quais cada educador/a se compromete no seu agir/ser quotidiano.

\section{Referências bibliográficas}

Arendt, H. (2001). A Condição Humana. Lisboa: Relógio D’Água.

Baker, A., Jensen, P., \& Kolb, D. (2002). Conversational learning: an experiential approach to knowledge creation. Westport: Quorum Books.

Bogdan, R. \& Biklen, S. (1994). Investigação Qualitativa em Educação. Porto: Porto Editora.

Capul, M. \& Lemay, M. (2003). Da Educação à Intervenção Social (2. ${ }^{\circ}$ vol.). Porto: Porto Editora.

Comissão Europeia (2010). Renewed European Training Strategy of the Youth in Action Programme. Disponível em http://www.salto-youth.net/rc/training-and-cooperation/trainingstrategy/

Conselho da Europa e Comissão Europeia (2011). Pathways 2.0 towards recognition of non-formal learning/education and of youth work in Europe. Disponível em http://youth-partnership-eu.coe.int/youth-partnership/news/news_188.html

Emmerik, I. van (2012). Espaço em branco, intervisão e agência partilhada. In C. Múrias \& M. Koning (Coords.), Lideranças partilhadas: Percursos de literacia para a igualdade de género e qualidade de vida (pp. 91-97). Porto: Fundação Cuidar O Futuro \& Livpsic.

Fennes, H. \& Otten, H. (2008). Quality in non-formal education and training in the field of European youth work. Bonn: SALTO-YOUTH Training and Cooperation Resource Centre and EU-CoE Youth Partnership.

Freire, P. (1979). Conscientização: teoria e prática da libertação. São Paulo: Cortez \& Moraes.

García López, M. A. (2007). Mapping study of European-level training of trainers. Bonn: SALTO-YOUTH Training and Cooperation Resource Centre.

Hofmann, P. (2010). A 10 Years Learning Journey: 10 years Training of Trainers for European Youth Projects. Bonn: SALTO-YOUTH Training and Cooperation Resource Centre.

Jarvis, P. (1987). Adult Learning in the Social Context. London: Croom Helm. 
Knowles, M. et al. (1984). Andragogy in Action: Applying Modern Principles of Adult Education. San Francisco: Jossey-Bass.

Kolb, D. (1984). Experiential Learning: Experience as the Source of Learning and Development. Englewood Cliffs: Prentice-Hall.

Koning, M., Múrias, C., Ribeiro, R., Carvalho, A., \& Lopes, L. (2012). Lideranças Partilhadas. Caderno de Trabalho: Propostas de literacia para a igualdade de género e a qualidade de vida. Lisboa: Fundação Cuidar o Futuro.

Koning, M. (2006). Lugares Emergentes do Sujeito-Mulher. Viagem com Paulo Freire e Maria de Lourdes Pintasilgo. Porto: Afrontamento.

Koning, M. (2009). Abrandar no espaço em branco. Dar relevo ao fundo dos textos sobre a liderança. In E. Macedo \& M. de Koning (Coords.), Reinventado Lideranças: Género, educação e poder (pp. 71-95). Porto: Fundação Cuidar O Futuro \& Livpsic.

Koning, M. (2012). Lideranças partilhadas. A caminho de um novo paradigma? In C. Múrias \& M. de Koning (Coords.), Lideranças partilhadas: Percursos de literacia para a igualdade de género e qualidade de vida (pp. 17-57). Porto: Fundação Cuidar O Futuro \& Livpsic.

Lima, L. C. \& Afonso, A. J. (2006). Políticas Públicas, Novos Contextos e Actores em Educação de Adultos. In L. C. Lima (Org.), Educação Não Escolar de Adultos Iniciativas de Educação e Formação de Adultos em Contextos Associativos (pp. 205-229). Braga: Universidade do Minho - Unidade de Educação de Adultos.

Macedo, E. \& Macedo, A. (2012). Aprender pela Conversa: assim como e depois? In: C. Múrias \& M. de Koning (Coords.), Lideranças Partilhadas: Percursos de literacia para a igualdade de género e qualidade (pp. 223-237). Porto: Fundação Cuidar O Futuro \& Livpsic.

Otten, H. \& Ohana, Y. (2009). The Eight Key Competencies for Lifelong Learning: An appropriate framework within which to develop the competence of trainers in the field of European youth work or just plain politics? Bonn: IKAB and SALTO-YOUTH Training and Cooperation Resource Centre.

Payne, M. (2002). Teoria do Trabalbo Social Moderno. Coimbra: Quarteto.

Reason, P. \& Bradbury, H. (2001). Handbook of Action Research - Participative Inquiry and Practice. London: Sage.

Rogers, C. (1969). Freedom to Learn: A View of What Education Might Become. Columbus: Merrill.

Watkins, K. \& Marsick, V. (1993). Sculpting the Learning Organization: The Art of Systemic Change. San Francisco: Jossey-Bass. 